\title{
Degradation of propyl paraben by activated persulfate using iron-containing magnetic carbon xerogels: investigation of water matrix and process synergy effects
}

\author{
Maria Evangelia Metheniti ${ }^{1} \cdot$ Zacharias Frontistis $^{1} \cdot$ Rui S. Ribeiro $^{2,3}$. \\ Adrián M.T. Silva ${ }^{3} \cdot$ Joaquim L. Faria $^{3} \cdot$ Helder T. Gomes $^{2} \cdot$ Dionissios Mantzavinos $^{1}$ (D)
}

Received: 30 July 2017 / Accepted: 11 September 2017 / Published online: 6 October 2017

(C) Springer-Verlag GmbH Germany 2017

\begin{abstract}
An advanced oxidation process comprising an iron-containing magnetic carbon xerogel $(\mathrm{CX} / \mathrm{Fe})$ and persulfate was tested for the degradation of propyl paraben (PP), a contaminant of emerging concern, in various water matrices. Moreover, the effect of $20 \mathrm{kHz}$ ultrasound or light irradiation on process performance was evaluated. The pseudo-first order degradation rate of PP was found to increase with increasing SPS concentration $(25-500 \mathrm{mg} / \mathrm{L})$ and decreasing PP concentration (1690-420 $\mu \mathrm{g} / \mathrm{L})$ and solution $\mathrm{pH}$ (9-3). Furthermore, the effect of water matrix on kinetics was detrimental depending on the complexity (i.e., wastewater, river water, bottled water) and the concentration of matrix constituents (i.e., humic acid, chloride, bicarbonate). The simultaneous use of $\mathrm{CX} / \mathrm{Fe}$ and ultrasound as persulfate activators resulted in a synergistic effect, with the level of synergy (between 35 and 50\%) depending on the water matrix. Conversely, coupling $\mathrm{CX} / \mathrm{Fe}$ with simulated solar or UVA irradiation resulted in a cumulative effect in experiments performed in ultrapure water.
\end{abstract}

Responsible editor: Vítor Pais Vilar

Dionissios Mantzavinos

mantzavinos@chemeng.upatras.gr

1 Department of Chemical Engineering, University of Patras, Caratheodory 1, University Campus, GR-26504 Patras, Greece

2 Laboratory of Separation and Reaction Engineering-Laboratory of Catalysis and Materials (LSRE-LCM), Escola Superior de Tecnologia e Gestão, Instituto Politécnico de Bragança, Campus de Santa Apolónia, 5300-253 Bragança, Portugal

3 Laboratory of Separation and Reaction Engineering-Laboratory of Catalysis and Materials (LSRE-LCM), Faculdade de Engenharia, Universidade do Porto, Rua Dr. Roberto Frias, 4200-465 Porto, Portugal
Keywords Combined activation · Endocrine disruptor · Environmental sample $\cdot$ Heterogeneous catalyst $\cdot$ Kinetics . Synergy $\cdot$ Ultrasound

\section{Introduction}

Advanced oxidation processes (AOPs) have gained substantial attention in the past few decades for the treatment of various classes of contaminants in several different matrices, including, for example, micro-contaminants and/or pathogens of emerging concern in natural waters, industrial pollution, atmospheric pollution, and sludge/soil pollution (Barreca et al. 2015; Pace and Barreca 2013; Gonzalez-Bahamon et al. 2011). AOPs rely, primarily but not exclusively, on the action of highly reactive, non-selective hydroxyl radicals. In recent years, other reactive species such as the sulfate radicals $\left(\mathrm{SO}_{4}{ }^{-}\right)$have been evaluated as a potential method for water treatment.

Sulfate radicals $\left(E^{\mathrm{o}}=2.6 \mathrm{~V}\right)$ are generated through the activation of persulfate anion $\left(E^{\circ}=2.1 \mathrm{~V}\right.$ ) (Matzek and Carter 2016; Tsitonaki et al. 2010):

$\mathrm{S}_{2} \mathrm{O}_{8}{ }^{2-}+$ Activator $\rightarrow[$ sulfate radicals and anions $]$

Persulfate has several benefits including moderate cost, high stability, and aqueous solubility, as well as the fact that it is solid at ambient temperature, which facilitates its transport and storage (Lin et al. 2011). Persulfate activation can be achieved by several means including heat, ultraviolet light, ultrasound, microwaves, alkaline conditions, hydrogen peroxide, and transition metals such as iron, cobalt, copper, zinc, and manganese (Matzek and Carter 2016). Persulfate activation by ferrous ion has extensively been investigated mimicking classical Fenton reactions (Liu et al. 2014): 


$$
\begin{aligned}
& \mathrm{S}_{2} \mathrm{O}_{8}{ }^{2-}+\mathrm{Fe}^{2+} \rightarrow \mathrm{SO}_{4}{ }^{--}+\mathrm{SO}_{4}{ }^{2-}+\mathrm{Fe}^{3+} \\
& \mathrm{Fe}^{3+}+\mathrm{S}_{2} \mathrm{O}_{8}{ }^{2-} \rightarrow \mathrm{Fe}^{2+}+\mathrm{S}_{2} \mathrm{O}_{8}{ }^{--}
\end{aligned}
$$

Thus, the overall iron-catalyzed decomposition of persulfate can be described as follows:

$2 \mathrm{~S}_{2} \mathrm{O}_{8}{ }^{2-} \stackrel{F e(I I) \leftrightarrow F e(I I I)}{\longrightarrow} \mathrm{SO}_{4}{ }^{--}+\mathrm{SO}_{4}{ }^{2-}+\mathrm{S}_{2} \mathrm{O}_{8}{ }^{--}$

To eliminate the need of an extra treatment stage to remove iron in homogeneous Fenton and alike systems, heterogeneous catalysts may be employed. In this perspective, novel magnetic carbon xerogels (CXs), consisting of interconnected carbon microspheres with iron and/or cobalt microparticles embedded in their structure, have recently been synthesized, characterized and tested successfully for the oxidation of the antibiotic sulfamethoxazole in water using hydrogen peroxide as the source of hydroxyl radicals. These materials exhibited high activity and good stability and they were also magnetically recoverable post-treatment (Ribeiro et al. 2016).

Parabens are esters of p-hydroxybenzoic acid that have relatively recently been recognized as emerging contaminants due to their estrogenic and anti-androgenic effects on human health even at concentrations as low as ng/L (Chen et al. 2017). They have been extensively used as preservatives in foodstuff, pharmaceuticals, cosmetics, and personal care products (Kapelewska et al. 2016), and they are released into the environment mainly through municipal wastewater discharges due to their insufficient biodegradation (Chen et al. 2017; Dhaka et al. 2017). In this respect, only recently has the treatment of parabens been investigated by AOPs (including photochemical AOPs, sonication, Fenton oxidation, electrochemical oxidation, and ozonation), as well as separation processes (including adsorption and membranes) (Chen et al. 2017). More importantly, the degradation of parabens by persulfate oxidation has merely been reported in a handful of studies. Chen et al. (2017) studied the degradation of methyl and ethyl parabens by heat-activated persulfate oxidation up to $60^{\circ} \mathrm{C}$, while Dhaka et al. (2017) studied the degradation of methyl paraben by UV-activated persulfate oxidation. We have recently demonstrated that the heat- (Frontistis et al. 2017) and ultrasound-activated (Papadopoulos et al. 2016) persulfate can successfully degrade ethyl paraben.

Within this context, this work reports the application of the novel $\mathrm{CX} / \mathrm{Fe}$-activated persulfate system for the degradation of propyl paraben (PP) in various water matrices. Emphasis is given on (i) the effect of water quality (i.e., in the presence of several non-target inorganic and organic constituents) on the degradation rates of PP at environmentally realistic concentrations (i.e., at the $\mu \mathrm{g} / \mathrm{L}$ level) and (ii) the effects of coupling $\mathrm{CX} / \mathrm{Fe}$ with another persulfate activator, i.e., low frequency ultrasound or light irradiation. To the best of our knowledge, this is the first work of this kind reported in the literature.

\section{Materials and methods}

\section{Catalyst and chemicals}

A monometallic carbon xerogel consisting of interconnected carbon microspheres embedded with iron microparticles (CX/ $\mathrm{Fe})$ was employed as a catalyst to activate persulfate. The catalyst has a BET specific surface area of $510 \mathrm{~m}^{2} / \mathrm{g}$ and an iron content of $6.5 \mathrm{wt} \%$. The full information regarding catalyst synthesis and characterization is given elsewhere (Ribeiro et al. 2016).

Propyl paraben (PP, $\mathrm{C}_{10} \mathrm{H}_{12} \mathrm{O}_{3}$, CAS number 80-05-7) and sodium persulfate ( $\mathrm{SPS}, \mathrm{Na}_{2} \mathrm{~S}_{2} \mathrm{O}_{8}, 99+\%$, CAS number 7775 27-1) were purchased from Sigma-Aldrich. Humic acid (technical grade), sodium chloride (99.8\%), sodium hydroxide (98\%), sodium bicarbonate, boric acid (>99.8\%), and sulphuric acid (95\%) were also obtained from Sigma-Aldrich. Potassium dihydrogen phosphate was supplied by Millipore. All chemicals were used as received, without further purification.

\section{Water matrices}

The following water matrices were employed: (i) ultrapure water (UPW, $\mathrm{pH}=6 ; 0.056 \mu \mathrm{S} / \mathrm{cm}$ conductivity); (ii) secondary treated wastewater (WW, $\mathrm{pH}=8 ; 7 \mathrm{mg} / \mathrm{L}$ total organic carbon (TOC); $1.1 \mathrm{mg} / \mathrm{L}$ total suspended solids; $21 \mathrm{mg} / \mathrm{L}$ chemical oxygen demand; $311 \mu \mathrm{S} / \mathrm{cm}$ conductivity; $30 \mathrm{mg} / \mathrm{L}$ sulfates; $0.44 \mathrm{mg} / \mathrm{L}$ chlorides), collected from the wastewater treatment plant of the University of Patras campus, Greece; (iii) commercially available bottled water $(\mathrm{BW}, \mathrm{pH}=7.5 ; 396 \mu \mathrm{S} / \mathrm{cm}$ conductivity; $211 \mathrm{mg} / \mathrm{L}$ bicarbonates; $15 \mathrm{mg} / \mathrm{L}$ sulfates; $9.8 \mathrm{mg} /$ $\mathrm{L}$ chlorides); (iv) surface water taken from a river in the region of Athens, Greece ( $\mathrm{pH}=7.5 ; 491 \mu \mathrm{S} / \mathrm{cm}$ conductivity; TOC $=2.7 \mathrm{mg} / \mathrm{L} ; 274 \mathrm{mg} / \mathrm{L}$ sulfates; $5 \mathrm{mg} / \mathrm{L}$ chlorides $).$

\section{Experimental procedure}

Experiments were conducted in a cylindrical glass reaction vessel of $250 \mathrm{~mL}$ capacity which was open to the atmosphere. The appropriate volume of a stock PP solution at a concentration of $80 \mathrm{mg} / \mathrm{L}$ was mixed with the water matrix to achieve the desired PP concentration (typically $420 \mu \mathrm{g} / \mathrm{L}$ ) and $120 \mathrm{~mL}$ of the resulting solution were loaded in the vessel. The appropriate amount of SPS and CX/Fe were then added and the reaction took place under magnetic stirring at a constant temperature of $25 \pm 1{ }^{\circ} \mathrm{C}$. The solution was buffered at acidic $(\mathrm{pH}=3)$, near-neutral $(\mathrm{pH}=6)$ or alkaline $(\mathrm{pH}=9)$ conditions using $\mathrm{H}_{2} \mathrm{SO}_{4}, \mathrm{KH}_{2} \mathrm{PO}_{4}$, and a mixture of $\mathrm{NaOH}$ and $\mathrm{H}_{3} \mathrm{BO}_{3}$, respectively. Samples of $1.2 \mathrm{~mL}$ were periodically withdrawn 
Fig. 1 Effect of buffered solution $\mathrm{pH}$ on $420 \mu \mathrm{g} / \mathrm{L}$ PP degradation with $63 \mathrm{mg} / \mathrm{L} \mathrm{CX} / \mathrm{Fe}$ and $500 \mathrm{mg} /$ L SPS in UPW

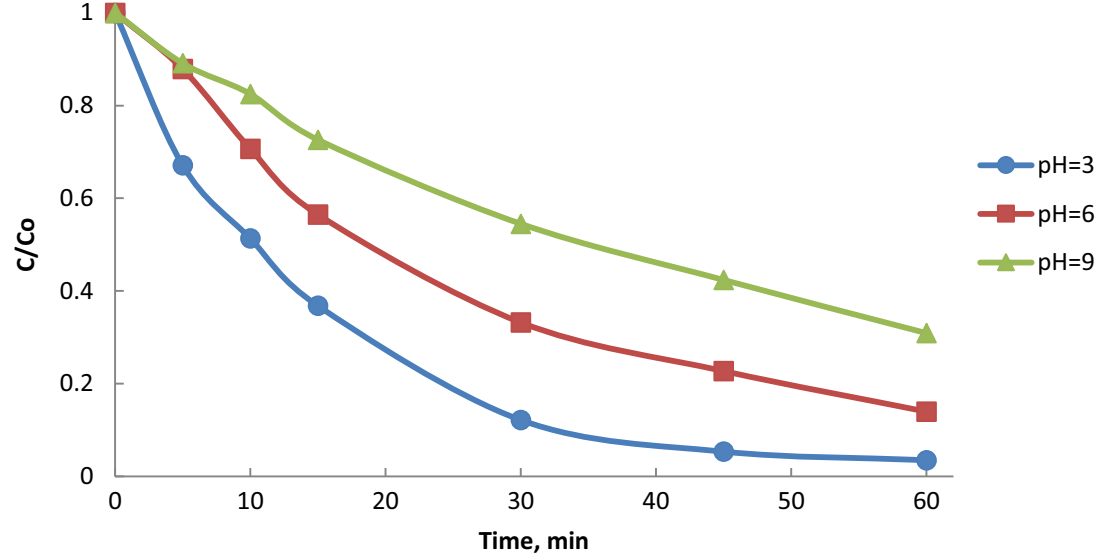

from the vessel, quenched with methanol, filtered, and finally analyzed by liquid chromatography.

For those experiments where ultrasound was employed to activate the process, a Branson 450 horn-type digital sonifier operating at a frequency of $20 \mathrm{kHz}$ and an actual power density of $36 \mathrm{~W} / \mathrm{L}$ was employed. Ultrasound irradiation was emitted through a $1 \mathrm{~cm}$ in diameter titanium tip which was positioned in the middle of the vessel at a distance of $3 \mathrm{~cm}$ from the bottom.

For certain experiments, light was employed to activate the process; this was done using either a $25 \mathrm{~W}$ black light lamp emitting predominantly at $365 \mathrm{~nm}$ (UVA) or a solar simulator (Oriel, model LCS-100) equipped with a $100 \mathrm{~W}$ xenon, ozone-free lamp. The photon flux, determined by chemical actinometry, was $4.810^{-7}$ and $7.310^{-7}$ einstein/(L.s) for the black light lamp and the solar simulator, respectively.

Most of the experiments were performed in duplicate and mean values $(<5 \%$ difference) are quoted as results.

\section{Analytical methods}

High performance liquid chromatography (HPLC: Alliance 2695, Waters) was employed to monitor the concentration of PP. Separation was achieved on a Kinetex XB-C18 100A column $(2.6 \mu \mathrm{m}, 2.1 \times 50 \mathrm{~mm})$ and a $0.5 \mu \mathrm{m}$ inline filter (KrudKatcher Ultra) both purchased from Phenomenex. The
Table 1 Computed rate constants and coefficients of linear regression according to Eq. (5) for PP degradation with $63 \mathrm{mg} / \mathrm{L} \mathrm{CX/}$ $\mathrm{Fe}$ under various experimental conditions

\begin{tabular}{|c|c|c|c|c|c|}
\hline $\mathrm{PP}, \mu \mathrm{g} / \mathrm{L}$ & $\mathrm{SPS}, \mathrm{mg} / \mathrm{L}$ & $\mathrm{pH}$ & Matrix & $10^{3} \mathrm{k}, \min ^{-1}$ & $r^{2}, \%$ \\
\hline 420 & 500 & 3 & UPW & 66.8 & 99.7 \\
\hline 420 & 500 & 6 & UPW & 33.5 & 99.4 \\
\hline 420 & 500 & 9 & UPW & 19.6 & 99.8 \\
\hline 420 & 0 & 3 & UPW & 21.6 & 96.8 \\
\hline 420 & 25 & 3 & UPW & 20.1 & 96.9 \\
\hline 420 & 100 & 3 & UPW & 20.6 & 98.6 \\
\hline 420 & 200 & 3 & UPW & 25.3 & 98.8 \\
\hline 420 & 400 & 3 & UPW & 42.6 & 99.2 \\
\hline 420 & 750 & 3 & UPW & 68.6 & 99.5 \\
\hline 420 & 500 & 3 & BW & 55 & 99.9 \\
\hline 420 & 500 & 3 & River water & 24.1 & 99.7 \\
\hline 420 & 500 & 3 & WW & 16.2 & 98.9 \\
\hline 1690 & 500 & 3 & UPW & 18.2 & 97.7 \\
\hline 420 & 500 & 3 & $\mathrm{UPW}+5 \mathrm{mg} / \mathrm{L} \mathrm{HA}$ & 23.8 & 99.3 \\
\hline 420 & 500 & 3 & UPW + 10 mg/L HA & 19.8 & 98.8 \\
\hline 420 & 500 & 3 & $\mathrm{UPW}+250 \mathrm{mg} / \mathrm{L} \mathrm{Cl}^{-}$ & 34.5 & 99.3 \\
\hline 420 & 500 & 3 & $\mathrm{UPW}+500 \mathrm{mg} / \mathrm{L} \mathrm{Cl}^{-}$ & 38.4 & 99.3 \\
\hline 420 & 500 & 3 & $\mathrm{UPW}+1000 \mathrm{mg} / \mathrm{L} \mathrm{Cl}^{-}$ & 41.2 & 98.6 \\
\hline 420 & 500 & 3 & $\mathrm{UPW}+125 \mathrm{mg} / \mathrm{L} \mathrm{BIC}$ & 50 & 98.9 \\
\hline 420 & 500 & 3 & $\mathrm{UPW}+500 \mathrm{mg} / \mathrm{L} \mathrm{BIC}$ & 44.5 & 99.9 \\
\hline 420 & 500 & 3 & $\mathrm{UPW}+3000 \mathrm{mg} / \mathrm{L} \mathrm{BIC}$ & 26.7 & 99.1 \\
\hline
\end{tabular}


Fig. 2 Effect of SPS concentration on $420 \mu \mathrm{g} / \mathrm{L} \mathrm{PP}$ degradation with $63 \mathrm{mg} / \mathrm{L} \mathrm{CX/Fe}$ in UPW and $\mathrm{pH}=3$

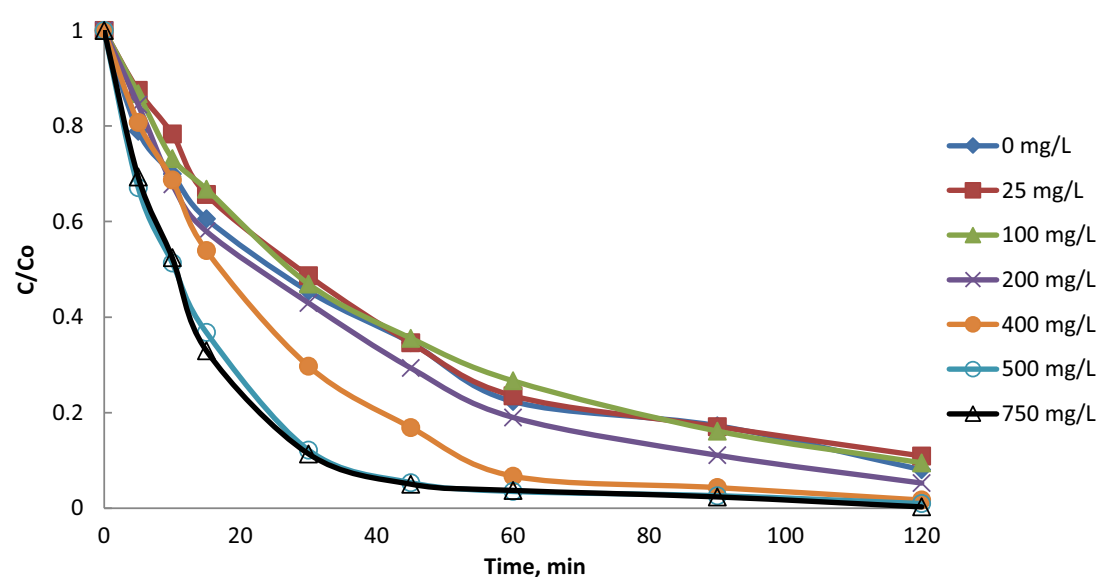

mobile phase consisting of 75:25 water to acetonitrile eluted isocratically at $0.35 \mathrm{~mL} / \mathrm{min}$ and $45^{\circ} \mathrm{C}$, while the injection volume was $40 \mu \mathrm{L}$. Detection was achieved through a photodiode array detector (Waters 2996 PDA detector, detection $\lambda=254 \mathrm{~nm})$.

\section{Results and discussion}

\section{Effect of operating conditions}

The effect of solution $\mathrm{pH}$ on PP degradation was studied at 3 , 6 , and 9 and the results are shown in Fig. 1. The solution was buffered at each $\mathrm{pH}$ value, which remained unchanged during the reaction.

Assuming that PP degradation follows a pseudo-first order rate expression, the natural logarithms of the profiles of Fig. 1 were plotted against time to compute apparent rate constants, $k$, (data fitting is not shown for brevity), i.e.,

$\operatorname{Ln}(\mathrm{Co} / \mathrm{C})=k t$
Rate constants take values equal to $66.810^{-3}, 33.510^{-3}$, and $19.610^{-3} \mathrm{~min}^{-1}$ at $\mathrm{pH}$ values of 3,6 , and 9, respectively. Table 1 summarizes the computed rate constants of all the experiments presented in section 3.1 for up to $90-95 \% \mathrm{PP}$ conversion.

The $\mathrm{pH}$ point of zero charge of the catalyst is 6.6 (Ribeiro et al. 2016). When the solution $\mathrm{pH}$ is below this value, the catalyst surface becomes positively charged. Consequently, the adsorption and subsequent activation of persulfate anions onto the catalysts is favored at $\mathrm{pH}$ values of 3 and 6 due to the electrostatic attraction between the catalyst surface and the persulfate ions but it decreases at $\mathrm{pH}=9$ due to electrostatic repulsion. Furthermore, PP has a pKa value of 8.4 (Haman et al. 2015). When the solution $\mathrm{pH}$ is above this value, $\mathrm{PP}$ is negatively charged; therefore, electrostatic repulsions between the substrate and the catalyst can also explain the decreased reactivity recorded at $\mathrm{pH}=9$. In addition, persulfate conversion to sulfate radicals may be accelerated at acidic environments due to acid-catalyzed reactions, as has been discussed by Chen et al. (2017), who also reported that the heat-activated persulfate
Fig. 3 Effect of the water matrix on $420 \mu \mathrm{g} / \mathrm{L}$ PP degradation with $63 \mathrm{mg} / \mathrm{L} \mathrm{CX} / \mathrm{Fe}, 500 \mathrm{mg} / \mathrm{L}$ SPS and $\mathrm{pH}=3$

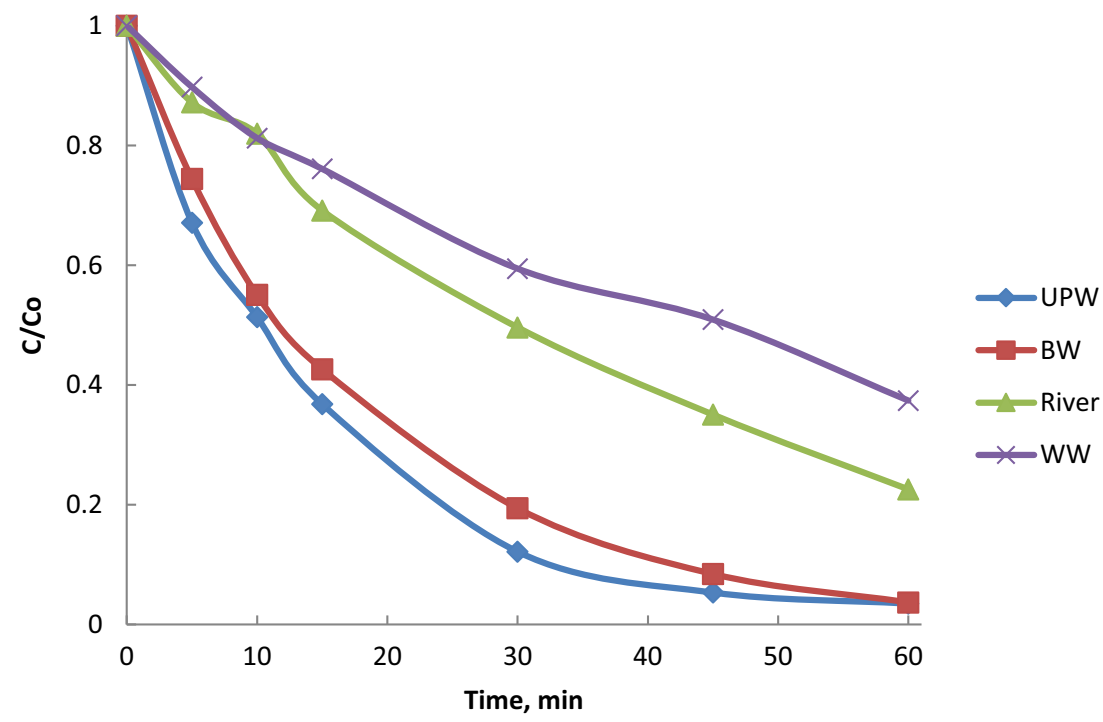


Fig. 4 Effect of a humic acid, $b$ $\mathrm{NaCl}$, and $\mathbf{c}$ bicarbonates spiked in UPW on $420 \mu \mathrm{g} / \mathrm{L}$ PP degradation with $63 \mathrm{mg} / \mathrm{L} \mathrm{CX} / \mathrm{Fe}$, $500 \mathrm{mg} / \mathrm{L}$ SPS and $\mathrm{pH}=3$
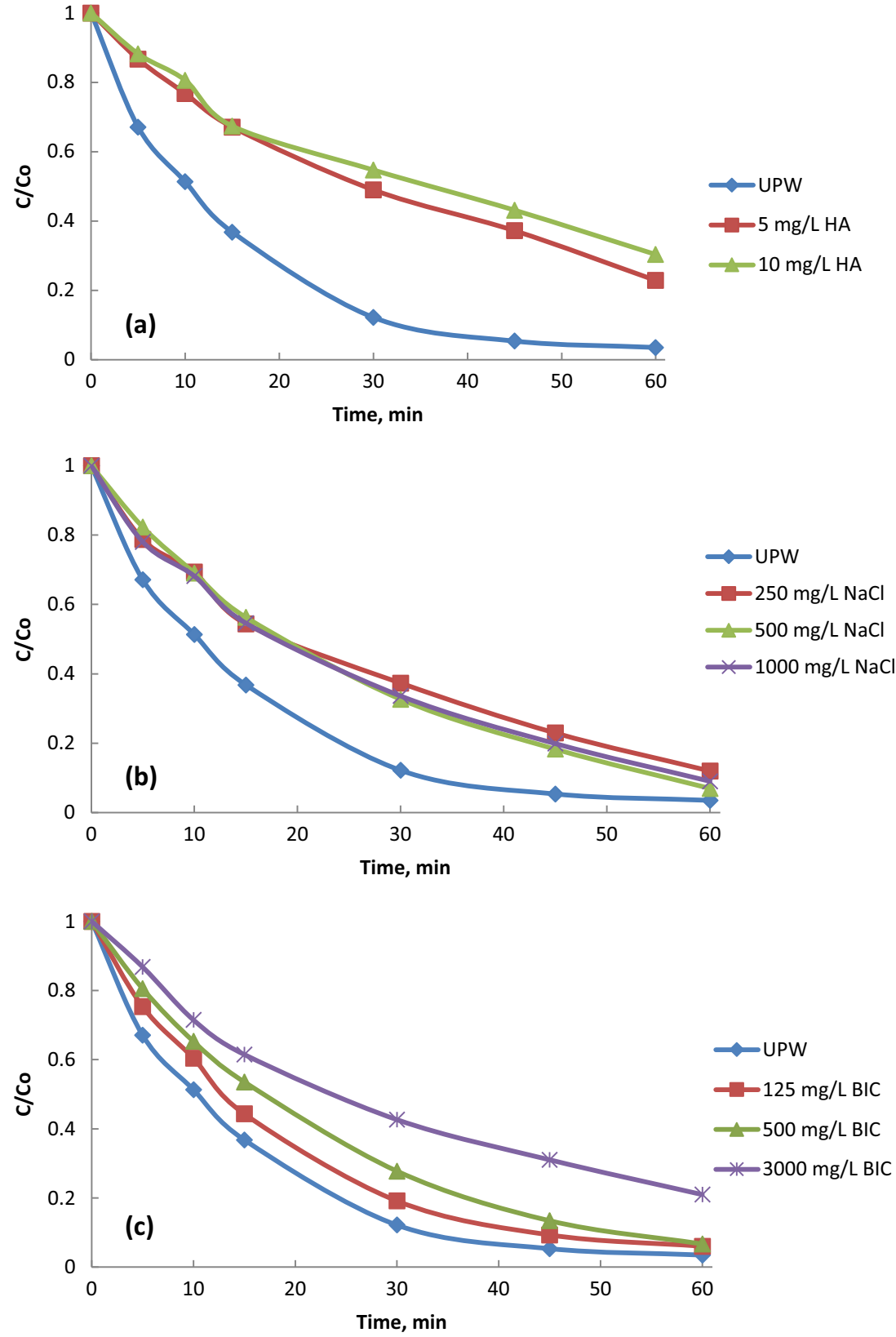

degradation of ethyl and methyl parabens was promoted as the solution $\mathrm{pH}$ decreased from 9 to 7 to 5 .

Sulfate radicals react with water at all $\mathrm{pH}$ values leading to the formation of hydroxyl radicals, which become the main oxidizing species at alkaline conditions (Dhaka et al. 2017; Matzek and Carter 2016; Zhao et al. 2014):

$\mathrm{SO}_{4}{ }^{--}+\mathrm{H}_{2} \mathrm{O} \rightarrow \mathrm{SO}_{4}{ }^{2-}+\mathrm{HO}^{\bullet}+\mathrm{H}^{+}$

$\mathrm{SO}_{4}{ }^{--}+\mathrm{OH}^{-} \rightarrow \mathrm{SO}_{4}{ }^{2-}+\mathrm{HO}^{\circ}$

Although sulfate radicals have a lower redox potential than hydroxyl radicals, they are more selective towards certain organics (Velosa and Nascimento 2017; Zhou et al. 2017;
Lutze et al. 2015), and this may justify the reactivity recorded at lower $\mathrm{pH}$ values, where sulfate radicals prevail. Dhaka et al. (2017) reported that the UV-activated persulfate degradation of methyl paraben at $\mathrm{pH}=9$, where hydroxyl radicals were the dominant species, was lower than at $\mathrm{pH}=3$ or $\mathrm{pH}=6.5$, where sulfate radicals prevailed. In view of these results, all subsequent experiments were performed at $\mathrm{pH}=3$.

The effect of changing SPS concentration on PP degradation is depicted in Fig. 2. Interestingly, adsorption of PP onto the catalyst surface occurs to a considerable extent in the absence of SPS, while the effect of oxidation is not evident below $200 \mathrm{mg} /$ L SPS concentration; Table 1 shows the respective rate constants including the experiment without SPS, with the 
Fig. 5 Effect of initial PP concentration on its degradation with $63 \mathrm{mg} / \mathrm{L} \mathrm{CX/Fe}$ and $500 \mathrm{mg} /$ $\mathrm{L}$ SPS in UPW and $\mathrm{pH}=3$

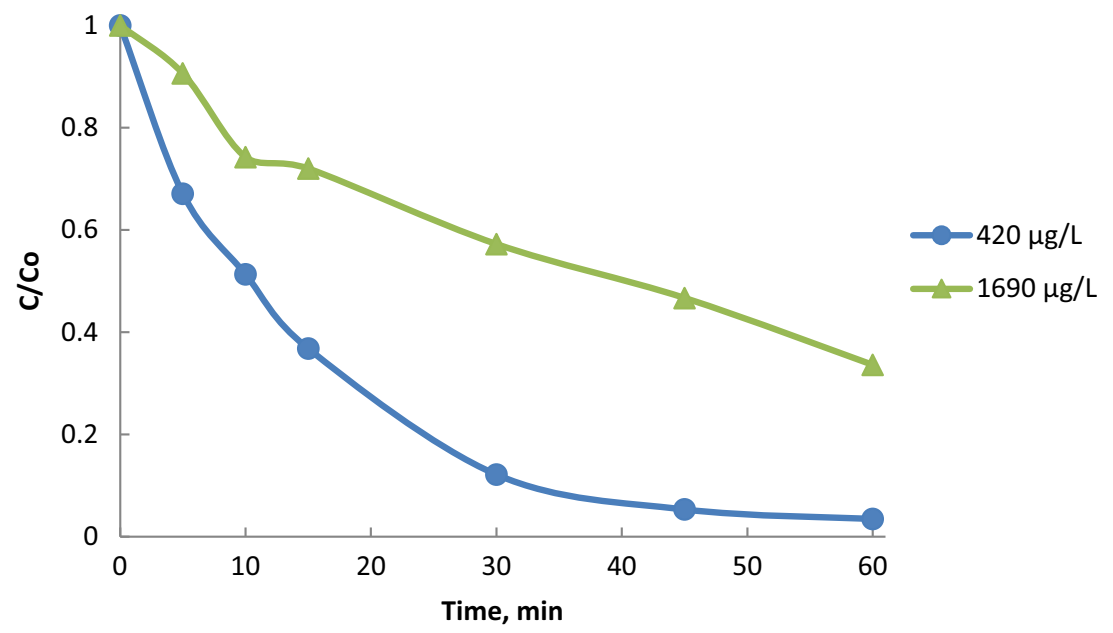

value being $20.8 \pm 0.710^{-3} \mathrm{~min}^{-1}$ in the $0-100 \mathrm{mg} / \mathrm{L}$ SPS concentration range. Thereafter, degradation increases with increasing SPS concentration up to $500 \mathrm{mg} / \mathrm{L}$, while a further SPS increase to $750 \mathrm{mg} / \mathrm{L}$ has no effect on degradation.

The effect of the water matrix on PP degradation is shown in Fig. 3. Relative to the experiment in UPW, the rate (based on the computed rate constants shown in Table 1) decreases by 18,64 , and $76 \%$ in bottled water (BW), river water, and secondary treated wastewater (WW), respectively. Natural waters and waste waters contain various inorganic and organic, non-target constituents that may compete with the substrate for both the active catalyst sites and the generated radicals.

The individual effects of certain matrix constituents are shown in Fig. 4. As can be seen in Fig. 4a, humic acid (HA), which is considered as a model compound of the macro-molecules typically found in natural (NOM) and effluent organic matter (EfOM), has a detrimental effect on PP degradation; the rate, relative to UPW, decreases by about $65-70 \%$ in the presence of 5-10 mg/L HA. In their work, Boni and Sbaffoni (2012) reported the detrimental effect of NOM on the iron-activated persulfate oxidation of real groundwater samples contaminated by benzene, 1,4-dichlorobenzene and 1,2-dichloropropane.

Figure $4 \mathrm{~b}$ shows the detrimental effect of chloride in the range $250-1000 \mathrm{mg} / \mathrm{L}$; it must be noted here that these concentrations were tested since the river water contained chloride in the order of $100 \mathrm{mg} / \mathrm{L}$ possibly due to contamination from a nearby industrially contaminated site. Relative to the experiment without chloride, the rate decreases by $43 \pm 5 \%$ in the presence of chloride. Sulfate radicals primarily react with chloride to form chlorine radicals that further react with chloride to form the dichloride radical (Lutze et al. 2015; Bennedsen et al. 2012; Fang et al. 2012):

$\mathrm{SO}_{4}{ }^{--}+\mathrm{Cl}^{-} \rightleftarrows \mathrm{SO}_{4}{ }^{2-}+\mathrm{Cl}^{\bullet}$

$\mathrm{Cl}^{\bullet}+\mathrm{Cl}^{-} \rightleftarrows \mathrm{Cl}_{2}^{\cdot-}$
Depending on the experimental conditions under consideration, several consecutive reactions may take place leading to the formation of additional chlorine-containing radicals such as $\mathrm{ClO}_{2}{ }^{\circ}, \mathrm{ClO}^{\circ}$, and $\mathrm{HOCl}^{-}$(Lutze et al. 2015). Overall, the presence of chloride seems to influence the distribution of reactive species and, consequently, degradation kinetics. Previous studies have reported the negative effect of chloride on the persulfate oxidation of polychlorinated biphenyls (Fang et al. 2012), acetaminophen (at chloride concentrations greater than $350 \mathrm{mg} / \mathrm{L}$ ) (Tan et al. 2014), and trichloroethene (at $1750 \mathrm{mg} / \mathrm{L}$ chloride concentration) (Wu et al. 2014).

Figure $4 \mathrm{c}$ shows the effect of bicarbonate (BIC) addition in the range $125-3000 \mathrm{mg} / \mathrm{L}$. Although the presence of bicarbonate is not favored at $\mathrm{pH}$ values below 4 , where the equilibrium of carbonate species is shifted entirely towards $\mathrm{CO}_{2}$ (Ibanez et al. 2007), there appears to be a negative effect on PP degradation. It must be noticed here that the solution was not purged prior to the experiment to accelerate the release of $\mathrm{CO}_{2}$ in the atmosphere and, consequently, the presence of bicarbonate at concentrations presumably lower than the nominal values may scavenge both sulfate and hydroxyl radicals to form carbonate radicals (Vicente et al. 2011; Waldemer et al. 2007):

$$
\begin{aligned}
& \mathrm{HCO}_{3}{ }^{-}+\mathrm{SO}_{4}{ }^{-} \rightarrow \mathrm{CO}_{3}{ }^{-}+\mathrm{SO}_{4}{ }^{--}+\mathrm{H}^{+} \\
& \mathrm{HCO}_{3}{ }^{-}+\mathrm{HO}^{-} \rightarrow \mathrm{CO}_{3}{ }^{--}+\mathrm{H}_{2} \mathrm{O}
\end{aligned}
$$

Relative to the experiment without bicarbonate, the rate decreases by 25,35 , and $60 \%$ at bicarbonate nominal concentrations of 125,500 and $3000 \mathrm{mg} / \mathrm{L}$. Earlier studies have reported the detrimental effect of bicarbonate on the heat-activated persulfate oxidation of chlorinated ethenes (Waldemer et al. 2007), as well as on the iron-activated persulfate oxidation of diuron (Vicente et al. 2011).

Regarding the effects of humic acid, chloride, and bicarbonate on PP degradation, the results reported in this work are consistent with those of Chen et al. (2017) and 
Fig. 6 Synergy effects on $420 \mu \mathrm{g} / \mathrm{L}$ PP degradation in a UPW, b BW, and $\mathbf{c}$ WW. Other conditions: $63 \mathrm{mg} / \mathrm{L} \mathrm{CX} / \mathrm{Fe}$, $500 \mathrm{mg} / \mathrm{L} \mathrm{SPS}, \mathrm{pH}=3,36 \mathrm{~W} / \mathrm{L}$ of US power. Captions as in (a)
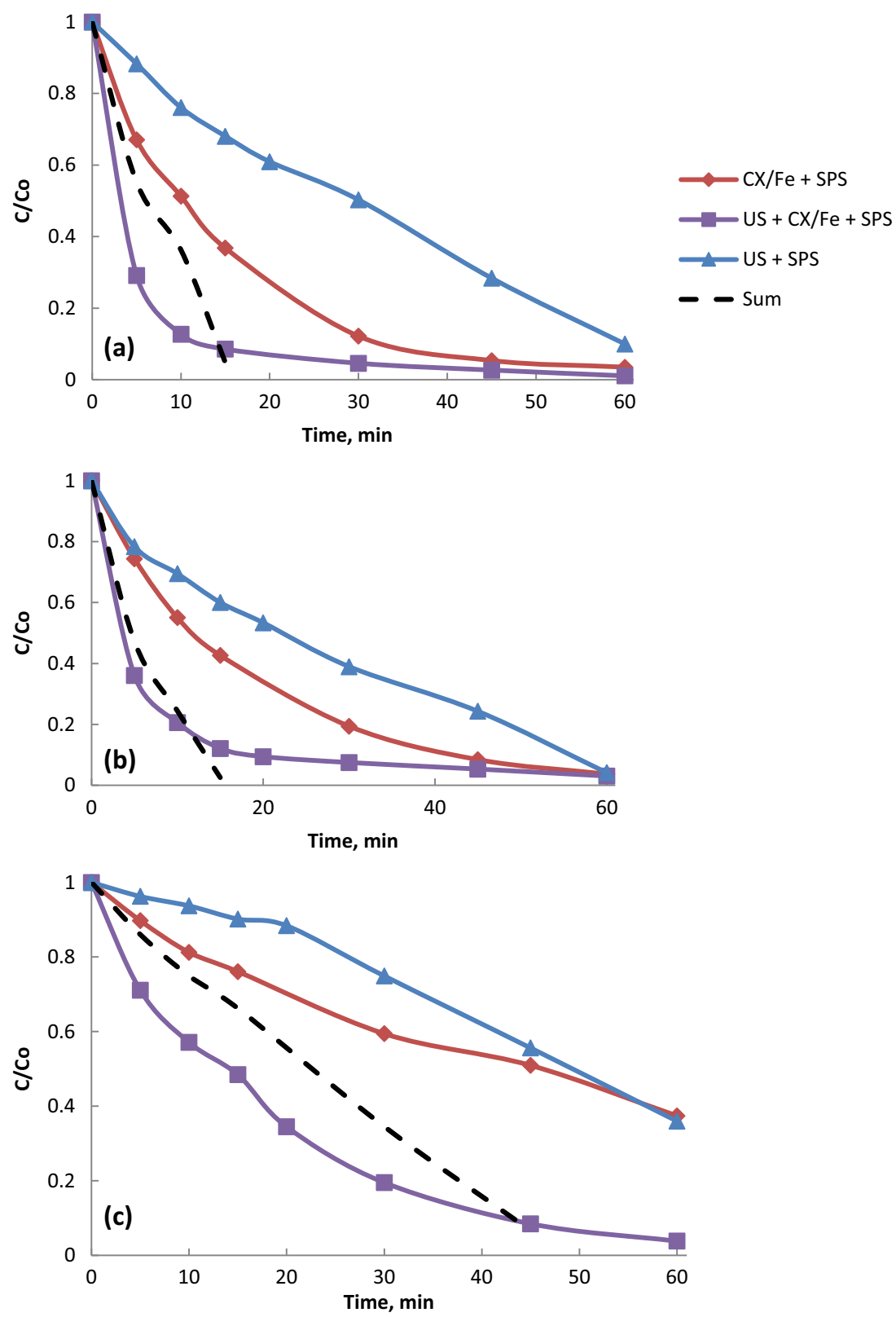

Dhaka et al. (2017) who found similar detrimental effects on methyl and ethyl parabens degradation by persulfate oxidation.

A final experiment was performed at an initial PP concentration of $1690 \mu \mathrm{g} / \mathrm{L}$, resulting in decreased kinetics (Fig. 5). A 4-fold increase in PP concentration (from 420 to $1690 \mu \mathrm{g} / \mathrm{L}$ ) gives a nearly 4-fold decrease in rate constants (from $66.810^{-3}$ to $18.210^{-3} \mathrm{~min}^{-1}$, i.e., a $73 \%$ reduction), thus highlighting the need to avoid working with unrealistically high concentrations. Dhaka et al. (2017) reported an 8-fold decrease in methyl paraben degradation kinetics when the initial paraben concentration increased from 3 to $10 \mathrm{mg} / \mathrm{L}$. Contaminants of emerging concern in environmentally relevant samples typically exist at the $n g / L-\mu g / L$ concentration levels; in this respect, working at concentrations that are three or more orders of magnitude greater introduces an equivalent matrix effect. This is clearly demonstrated comparing the almost equal rates of PP degradation at $1690 \mu \mathrm{g} / \mathrm{L}$ in UPW (Fig. 5) and at $420 \mu \mathrm{g} / \mathrm{L}$ in wastewater (Fig. 3). At a simple level, the rate of degradation depends on the concentration ratio between the available oxidizing species and the (target and oxidizable, non-target) matrix constituents. As the concentration of the latter increases, the concentration of the former becomes the limiting factor in dictating kinetics.

\section{Coupling with ultrasound or light irradiation}

Since persulfate can be activated by several means, the effect of ultrasound irradiation on PP degradation was evaluated and the results are shown in Fig. 6 for three matrices, i.e., UPW, $\mathrm{BW}$, and WW. When SPS is activated by $20 \mathrm{kHz}$ ultrasound, 
90\% PP degradation is achieved in 60 min in UPW (Fig. 6a); half this time is needed for the same degradation when SPS is activated by the $\mathrm{CX} / \mathrm{Fe}$ catalyst. Notably, when the two activators are used together, the time needed for $90 \%$ conversion decreases to $10 \mathrm{~min}$. If this were the result of a purely cumulative effect, the concentration-time profile of the combined process would be represented by the dashed line; evidently, the interaction is synergistic since the rate of the combined process is greater than the sum of the rates of the individual processes, as can be seen in Table 2. Similar findings occur for the other two matrices. Synergy may be attributed to the ultrasound (i) facilitating mixing of the reactor contents, thus minimizing mass transfer limitations, and/or (ii) altering the surface properties of the heterogeneous catalyst (Frontistis and Mantzavinos 2017; Silva et al. 2007). The degree of synergy, $\mathrm{S}$, can be quantified as follows:

$S(\%)=100 \frac{k_{\text {combined }}-\sum_{1}^{n} k_{\mathrm{i}}}{k_{\text {combined }}}$

Where

$S\left\{\begin{array}{cc}>0 & \text { synergisticeffect } \\ =0 & \text { cumulativeeffect } \\ <0 & \text { antagonisticeffect }\end{array}\right.$

In Eq. (12), $k_{\mathrm{i}}$ is the rate constant of each individual process, while $k_{\text {combined }}$ is the rate constant of the combined process. The effect of process coupling is simply cumulative (additive) if $S=0$ but it becomes synergistic as $S$ becomes positive. Although not very common, process coupling may result in inhibitory (antagonistic) effects, thus leading to decreased degradation rates. A possible reason is the generation of large amounts of oxidizing species that may behave as selfscavengers. As seen in Table 2, the simultaneous activation of

Table 2 Computed rate constants and coefficients of linear regression according to Eq. (5) and synergy according to Eq. (12) for PP degradation at the conditions of Fig. 6

\begin{tabular}{lllll}
\hline SPS activation & Matrix & $10^{3} \mathrm{k}, \mathrm{min}^{-1}$ & $r^{2}, \%$ & $S, \%$ \\
\hline US & UPW & 26.2 & 98.4 & \\
$\mathrm{CX} / \mathrm{Fe}$ & UPW & 66.8 & 99.7 & \\
$\mathrm{US}+\mathrm{CX} / \mathrm{Fe}$ & $\mathrm{UPW}$ & 182 & 93.4 & 48.9 \\
$\mathrm{US}$ & BW & 31.8 & 99.2 & \\
$\mathrm{CX} / \mathrm{Fe}$ & BW & 55 & 99.9 & \\
$\mathrm{US}+\mathrm{CX} / \mathrm{Fe}$ & BW & 133 & 91.8 & 34.7 \\
$\mathrm{US}$ & WW & 13.9 & 90 & \\
$\mathrm{CX} / \mathrm{Fe}$ & WW & 16.2 & 98.9 & \\
$\mathrm{US}+\mathrm{CX} / \mathrm{Fe}$ & WW & 54.4 & 99.8 & 44.7 \\
\hline
\end{tabular}

persulfate by the catalyst and the ultrasound results in ca 35 $50 \%$ synergy depending on the water matrix.

In a final set of experiments, SPS activation was initiated by UVA or solar light irradiation and the results are summarized in Table 3. The rate of PP degradation by light-activated persulfate oxidation is nearly equal to that induced by $\mathrm{CX} /$ $\mathrm{Fe}$ activation (i.e., $\mathrm{ca} \pm 6 \%$ depending on the light source). Interestingly, the simultaneous activation of persulfate by either light source and the catalyst results in a cumulative effect since the value of $S$ is very close to zero.

\section{Catalyst reusability}

To evaluate the performance of the catalyst upon repeated use, the following procedure was adopted: fresh catalyst at $63 \mathrm{mg} /$ $\mathrm{L}$ concentration was mixed with $420 \mu \mathrm{g} / \mathrm{L} \mathrm{PP}$ and $500 \mathrm{mg} / \mathrm{L}$ SPS in UPW at $\mathrm{pH}=3$ and the mixture was left to react for $90 \mathrm{~min}$. At the end of this run (cycle 1), another $420 \mu \mathrm{g} / \mathrm{L}$ PP and $500 \mathrm{mg} / \mathrm{L}$ SPS were fed to the vessel and reacted for $90 \mathrm{~min}$, and this procedure was repeated four times (i.e., a total of 5 cycles including the run with the fresh catalyst). No catalyst conditioning or treatment was applied between the cycles. The 90-min conversion of PP was 91.2, 87.1, $85.2,78.5$, and $70.8 \%$ for each one of the 5 cycles, showing that the catalyst retains substantial activity upon repeated use. The partial loss of activity may be ascribed to the gradual accumulation of un-reacted PP and its transformation by-products, which is consistent with the detrimental effect of increased organic concentration on kinetics (i.e., as has been demonstrated in Figs. 3, 4a, and 5).

\section{Conclusions and final remarks}

The primary conclusions derived from this study are as follows:

1. Magnetic carbon xerogels containing iron can efficiently activate persulfate to sulfate radicals, and the approach

Table 3 Effect of UVA or solar light irradiation on PP degradation. Computed rate constants and coefficients of linear regression according to Eq. (5) and synergy according to Eq. (12). Conditions: $420 \mu \mathrm{g} / \mathrm{L} \mathrm{PP,}$ $500 \mathrm{mg} / \mathrm{L} \mathrm{SPS}, 63 \mathrm{mg} / \mathrm{L} \mathrm{CX} / \mathrm{Fe}, \mathrm{pH}=3$

\begin{tabular}{lllll}
\hline SPS activation & Matrix & $10^{3} \mathrm{k}, \mathrm{min}^{-1}$ & $r^{2}, \%$ & $S, \%$ \\
\hline UVA & UPW & 62 & 99.5 & \\
$\mathrm{CX} / \mathrm{Fe}$ & UPW & 66.8 & 99.7 & \\
$\mathrm{UVA}+\mathrm{CX} / \mathrm{Fe}$ & UPW & 130.8 & 99.7 & 1.5 \\
Solar & UPW & 70.1 & 98.2 & \\
$\mathrm{CX} / \mathrm{Fe}$ & UPW & 66.8 & 99.7 & \\
Solar+CX/Fe & UPW & 129.7 & 98.6 & -5.6 \\
\hline
\end{tabular}


was demonstrated for the treatment of propyl paraben, an endocrine disruptor of emerging concern. Unlike homogeneous iron-containing materials, carbon xerogels can readily be separated from the solution post-treatment.

2. Important factors that are likely to dictate process kinetics are the water matrix and the concentration levels of the contaminant under consideration. The interplay amongst the various non-target constituents of the matrix, the available reactive species, and the catalyst typically, but not always, lead to decreased degradation rates of the contaminant. In this work, this detrimental effect was demonstrated performing experiments with actual environmental matrices, as well as pure water spiked with anions and NOM. Moreover, excessive contaminant concentrations introduce an equivalent matrix effect.

3. Process integration is conceptually advantageous since it can enhance performance in a synergistic or additive way. This was demonstrated coupling the $\mathrm{CX} / \mathrm{Fe}$-persulfate system with ultrasound or light (UVA or simulated solar) irradiation. The simultaneous action of the catalyst and the ultrasound led to a synergistic effect, i.e., the efficiency of the combined process was greater than the sum of the efficiencies of the individual processes. Conversely, the simultaneous action of the catalyst and the light led to a cumulative effect with the efficiency of the combined process being nearly equal to the sum of the contributions of the individual processes.

Acknowledgments Dr. Zacharias Frontistis would like to thank the Greek State Scholarship Foundation (IKY) for providing him fellowship for conducting post-doctoral research in Greece through the "IKY Fellowships of Excellence for Postgraduate Studies in GreeceSiemens Programme" in the framework of the Hellenic RepublicSiemens Settlement Agreement.

Funding information Part of this work was financially supported by: Project POCI-01-0145-FEDER-006984 - Associate Laboratory LSRELCM funded by FEDER through COMPETE2020-Programa Operacional Competitividade e Internacionalização (POCI) — and by national funds through Fundação para a Ciência e a Tecnologia (FCT). Rui S. Ribeiro acknowledges the FCT individual Ph.D. grant SFRH/BD/ 94177/2013, with financing from FCT and the European Social Fund (through POPH and QREN). Dr. Adrian M.T. Silva acknowledges the FCT Investigator 2013 Programme (IF/01501/2013), with financing from the European Social Fund and the Human Potential Operational Programme.

\section{References}

Barreca S, Colmenares JJV, Pace A, Orecchio S, Pulgarin C (2015) Escherichia coli inactivation by neutral solar heterogeneous photoFenton (HPF) over hybrid iron/montmorillonite/alginate beads. J Environ Chem Eng 3(1):317-324

Bennedsen LR, Muff J, Sogaard EG (2012) Influence of chloride and carbonates on the reactivity of activated persulfate. Chemosphere 86(11):1092-1097
Boni MR, Sbaffoni S (2012) Chemical oxidation by sodium persulphate for the treatment of contaminated groundwater. Laboratory tests. Chem Eng Trans 28:157-162

Chen Y, Deng P, Xie P, Shang R, Wang Z, Wang S (2017) Heat-activated persulfate oxidation of methyl- and ethyl-parabens: effect, kinetics, and mechanism. Chemosphere 168:1628-1636

Dhaka S, Kumar R, Ali Khan M, Paeng KJ, Kurade MB, Kim SJ, Jeon BH (2017) Aqueous phase degradation of methyl paraben using UV-activated persulfate method. Chem Eng J 321:11-19

Fang GD, Dionysiou DD, Wang Y, Al-Abed SR, Zhou DM (2012) Sulfate radical-based degradation of polychlorinated biphenyls: effects of chloride ion and reaction kinetics. J Hazard Mater 227-228: 394-401

Frontistis Z, Mantzavinos D (2017) Advanced oxidation processes for wastewater treatment. In: Kalavrouziotis IK (ed) Wastewater and biosolids management, 1st edn. IWA Publishing, London, pp 131143

Frontistis Z, Antonopoulou M, Konstantinou I, Mantzavinos D (2017) Degradation of ethyl paraben by heat-activated persulfate oxidation: statistical evaluation of operating factors and transformation pathways. Environ Sci Pollut Res 24(2):1073-1084

Gonzalez-Bahamon LF, Hoyos DF, Benitez N, Pulgarin C (2011) New Fe-immobilized natural bentonite plate used as photo-Fenton catalyst for organic pollutant degradation. Chemosphere 82(8):11851189

Haman C, Dauchy X, Rosin C, Munoz JF (2015) Occurrence, fate and behavior of parabens in aquatic environments: a review. Water Res 68:1-11

Ibanez JG, Hernandez-Esparza M, Doria-Serrano C, Fregoso-Infante A, Singh MM (2007) Environmental chemistry fundamentals. Springer-Verlag, New York

Kapelewska J, Kotowska U, Wisniewska K (2016) Determination of personal care products and hormones in leachate and groundwater from Polish MSW landfills by ultrasound-assisted emulsification microextraction and GC-MS. Environ Sci Pollut Res 23(2):16421652

Lin YT, Liang C, Chen JH (2011) Feasibility study of ultraviolet activated persulfate oxidation of phenol. Chemosphere 82(8): $1168-1172$

Liu H, Bruton TA, Doyle FM, Sedlak DL (2014) In situ chemical oxidation of contaminated groundwater by persulfate: decomposition by $\mathrm{Fe}(\mathrm{III})-$ and $\mathrm{Mn}(\mathrm{IV})$-containing oxides and aquifer materials. Environ Sci Technol 48(17):10330-10336

Lutze HV, Kerlin N, Schmidt TC (2015) Sulfate radical-based water treatment in presence of chloride: formation of chlorate, interconversion of sulfate radicals into hydroxyl radicals and influence of bicarbonate. Water Res 72:349-360

Matzek LW, Carter KE (2016) Activated persulfate for organic chemical degradation: a review. Chemosphere 151:178-188

Pace A, Barreca S (2013) Environmental organic photochemistry: advances and perspectives. Curr Org Chem 17(24):3032-3041

Papadopoulos C, Frontistis Z, Antonopoulou M, Venieri D, Konstantinou I, Mantzavinos D (2016) Sonochemical degradation of ethyl paraben in environmental samples: statistically important parameters determining kinetics, by-products and pathways. Ultrason Sonochem 31:62-70

Ribeiro RS, Frontistis Z, Mantzavinos D, Venieri D, Antonopoulou M, Konstantinou I, Silva AMT, Faria JL, Gomes HT (2016) Magnetic carbon xerogels for the catalytic wet peroxide oxidation of sulfamethoxazole in environmentally relevant water matrices. Appl Catal B - Environ 199:170-186

Silva AMT, Nouli E, Carmo-Apolinario AC, Xekoukoulotakis NP, Mantzavinos D (2007) Sonophotocatalytic/ $\mathrm{H}_{2} \mathrm{O}_{2}$ degradation of phenolic compounds in agro-industrial effluents. Catal Tod 124(34):232-239 
Tan CQ, Gao NY, Zhou SQ, Xiao YL, Zhuang ZZ (2014) Kinetic study of acetaminophen degradation by UV-based advanced oxidation processes. Chem Eng J 253:229-236

Tsitonaki A, Petri B, Crimi M, Mosbaek H, Siegrist RL, Bjerg PL (2010) In situ chemical oxidation of contaminated soil and groundwater using persulfate: a review. Crit Rev Environ Sci Technol 40(1):5591

Velosa AC, Nascimento CAO (2017) Evaluation of sulfathiazole degradation by persulfate in Milli-Q water and in effluent of a sewage treatment plant. Environ Sci Pollut Res 24(7):6270-6277

Vicente F, Santos A, Romero A, Rodriguez S (2011) Kinetic study of diuron oxidation and mineralization by persulphate: effects of temperature, oxidant concentration and iron dosage method. Chem Eng J 170:127-135
Waldemer RH, Tratnyek PG, Johnson RL, Nurmi JT (2007) Oxidation of chlorinated ethenes by heat-activated persulfate: kinetics and products. Environ Sci Technol 41:1010-1015

Wu XL, Gu XG, Lu SG, Xu MH, Zang XK, Miao ZW, Qiu ZF, Sui Q (2014) Degradation of trichloroethylene in aqueous solution by persulfate activated with citric acid chelated ferrous ion. Chem Eng J 255:585-592

Zhao L, Hou H, Fujii A, Hosomi M, Li F (2014) Degradation of 1,4dioxane in water with heat- and $\mathrm{Fe}^{2+}$-activated persulfate oxidation. Environ Sci Pollut Res 21(12):7457-7465

Zhou L, Zhang Y, Ying R, Wang G, Long T, Li J, Lin Y (2017) Thermoactivated persulfate oxidation of pesticide chlorpyrifos in aquatic system: kinetic and mechanistic investigations. Environ Sci Pollut Res 24(12):11549-11558 